\title{
A new method to derive middle atmospheric temperature profiles using a combination of Rayleigh lidar and $\mathrm{O}_{2}$ airglow temperatures measurements
}

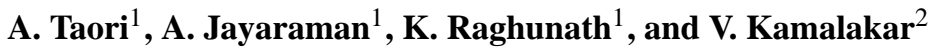 \\ ${ }^{1}$ National Amospheric Research Laboratory, Gadanki, 517 112, India \\ ${ }^{2}$ Dept. of Physics, S. V. University, Tirupati, 517 502, India
}

Correspondence to: A. Taori (alok.taori@gmail.com)

Received: 7 September 2011 - Revised: 23 November 2011 - Accepted: 25 November 2011 - Published: 5 January 2012

\begin{abstract}
The vertical temperature profiles in a typical Rayleigh lidar system depends on the backscatter photon counts and the CIRA-86 model inputs. For the first time, we show that, by making simultaneous measurements of Rayleigh lidar and upper mesospheric $\mathrm{O}_{2}$ temperatures, the lidar capability can be enhanced to obtain mesospheric temperature profile up to about $95 \mathrm{~km}$ altitudes. The obtained results are compared with instantaneous space-borne SABER measurements for a validation.
\end{abstract}

Keywords. Atmospheric composition and structure (Airglow and aurora; Instruments and techniques; General or miscellaneous)

\section{Introduction}

The mesosphere-lower thermosphere region $(75-100 \mathrm{~km})$ is the least explored region of the Earth's atmosphere with respect to temperatures. The mesospheric heat and momentum budget are highly variable due to (a) complex chemistry of odd oxygen and hydrogen and (b) gravity wave and tidal inputs of lower atmospheric origin and their feedback processes (e.g. Fritts and Alexander, 2003). The accessibility of upper mesospheric altitudes for temperature measurements has been very sparse, owing to various limitations in different ground based techniques. The prime methods to explore the thermal structures of this region are airglow monitoring (e.g. Taori and Taylor, 2006; Shepherd et al., 2006; Takahashi et al., 2011), Rayleigh lidar (e.g. Sivakumar et al., 2003; Chandra et al., 2005; Thurairajah et al., 2010), Resonance lidar (e.g. Friedman and Chu, 2007) and meteor radar (e.g. Dyrland et al., 2010); of which none provide simultaneous altitude coverage from $40-100 \mathrm{~km}$ regions, restricting a comprehensive study on the upward propagation of short period ( $0.5-2 \mathrm{~h})$ dynamical features that are very important for the coupling processes (e.g. Hocking, 1996). In recent times, there have been numerous studies utilizing space-borne measurements to study the upper mesospheric temperature variability, which have enriched our knowledge (e.g. Dou et al., 2009; Shepherd et al., 2006). However, temporal variability and evolution characteristics of the thermal structure remain unaddressed, owing to the limited passes of satellites over a given latitude-longitude sector. In summary, thrust of knowledge and further scientific consequences of thermal variability occurring at upper mesospheric altitudes require a robust ground based method capable of probing the low-middle and upper atmosphere near simultaneously.

Over Gadanki $\left(13.5^{\circ} \mathrm{N}, 79.2^{\circ} \mathrm{E}\right)$, Rayleigh lidar and mesospheric $\mathrm{OH}$ and $\mathrm{O}_{2}$ temperature measurements are made near simultaneously during moonless clear sky nights. As the $\mathrm{O}_{2}$ emission represents a layer at $95 \mathrm{~km}$ region with a thickness of about $5 \mathrm{~km}$, we propose to utilize the airglow data to improve the lidar temperature estimation algorithm. This is reasonable, because the present methods for lidar temperature estimates utilize the model values (e.g. CIRA86) at about $100 \mathrm{~km}$, which are well understood to be far from reality. The present work demonstrates that near simultaneous $\mathrm{O}_{2}$ temperature measurements can be used as an input in the lidar temperature retrieval method instead of the model values. We show that a significant improvement can be achieved in the altitude coverage of Rayleigh lidar temperature estimates. We use coincident space-borne measurements to cross check and validate our method, which are discussed in the following sections. 


\section{Measurement methods}

\subsection{Mesosphere Lower Thermosphere Photometer (MLTP)}

The MLTP measures two rotational lines of $\mathrm{OH}(6-2)$ and $\mathrm{O}_{2}$ $(0-1)$ bands together with thermospheric $\mathrm{O}\left({ }^{1} \mathrm{D}\right) 630.0 \mathrm{~nm}$ airglow emissions with the help of temperature controlled interference filters of full-width at half-maximum (FWHM) $\sim 0.4 \mathrm{~nm}$. The MLTP has F/2 optics and $4^{\circ}$ full field of view. It uses a photon counting module of Hamamatsu, Japan (H7421-50) as detector and photon counting unit C8855 for intensity measurements, which is connected to a computer. The rotation of interference filters and its interface with photon counting unit is controlled by menu-driven software. Using the relative photon count measurements, the mesospheric $\mathrm{OH}$ and $\mathrm{O}_{2}$ temperatures are estimated by the method described by Meriweather (1984). Details of MLTP and validation of results are discussed elsewhere (Taori et al., 2011, 2012a).

\subsection{Rayleigh lidar}

The Rayleigh lidar located at Gadanki uses a Nd:YAG laser and has maximum energy of $600 \mathrm{~mJ}$ per pulse at $532 \mathrm{~nm}$, pulse repetition frequency of $50 \mathrm{~Hz}$ and a pulse width of $7 \mathrm{~ns}$. A flat mirror oriented at $45^{\circ}$ to the beam axis directs the transmitted beam of $0.1 \mathrm{mrad}$ divergence vertically. The receiver employs a Newtonian telescope with primary mirror of effective diameter of $75 \mathrm{~cm}$ for the temperature measurement in the 30 to $80 \mathrm{~km}$ altitude region. An interference filter with full-width at half-maximum (FWHM) of $1.07 \mathrm{~nm}$ is used to reject the background light. The received signal is split into two channels in the ratio of 9:1: the high gain channel covers 50 to $80 \mathrm{~km}$ region where the signal is weak and the low gain channel covers 30 to $50 \mathrm{~km}$ where the signal is relatively strong. The signals are directed to photomultiplier tubes (Hamamatsu - R3234) and the outputs are first fed to pulse discriminators and then to a computer controlled photon-counting system. The data analysis for deriving the temperature profile is elaborated by Hauchecorne and Chanin (1980). Typically, for every $4 \mathrm{~min}$ one profile is obtained. More details on the Rayleigh lidar system used are given in Sivakumar et al. (2003).

\subsection{Sounding of the Atmosphere using Broadband Emission Radiometry (SABER)}

The Sounding of the Atmosphere using Broadband Emission Radiometry (SABER) is a high precision broadband radiometer that measures limb radiance emitted from the terrestrial atmosphere in 10 selected spectral bands, ranging from 1.27 to $15 \mu \mathrm{m}$, onboard the Thermosphere Ionosphere Mesosphere Energetics and Dynamics (TIMED) satellite orbiting the Earth at $74^{\circ}$ inclined plane. The temperature values are retrieved from SABER measurements of the atmospheric
$15 \mu \mathrm{m} \mathrm{CO}$ limb emission. Utilized here are the SABER 1.07 data, which have good temperature precision with error in the order of $\pm 1.4 \mathrm{~K}$ in lower stratosphere, $\pm 1 \mathrm{~K}$ in middle stratosphere and $\pm 2 \mathrm{~K}$ in upper stratosphere and lower mesosphere (e.g. Remsberg et al., 2008). The near coincidence SABER measured temperatures are used to cross check and validate our results.

\section{Analysis procedure}

The Raleigh lidar technique involves range resolved detection of molecular back-scattered laser radiation from altitudes above $30 \mathrm{~km}$, where the atmosphere is free from aerosols and the signal strength is proportional to molecular number density. Using the number density obtained from the CIRA-86 model for the height where the signal-to-noise ratio is fairly high, the constant of proportionality is evaluated and thereby the density profile $\rho(z)$ is derived. In existing methods, taking the pressure $(P)$ at the top of the height range $(100 \mathrm{~km})$ from the CIRA-86 model, the pressure profile is computed using the measured densities under an assumption that the atmosphere is in hydrostatic equilibrium. Further, using the ideal gas law, the temperature at a particular height " $z$ ", $T(z)$ is calculated using the expression:

$T\left(z_{i}\right)=\frac{M g\left(z_{i}\right) \Delta z}{R \log (1+X)}$

where

$X=\frac{\rho\left(z_{i}\right) g\left(z_{i}\right) \Delta z}{P\left(z_{i}+\Delta z / 2\right)}$

Here, $M$ is mean molecular weight of air. Further, the uncertainty in the derived temperature values is calculated using the expression:

$\frac{\delta T\left(z_{i}\right)}{T\left(z_{i}\right)}=\frac{\delta \log (1+X)}{\log (1+X)}=\frac{\delta X}{(1+X) \log (1+X)}$

In our modified scheme, we feed the actually measured temperature values from the $\mathrm{O}_{2}$ airglow emission measurements in Eq. (2) by deriving $X$ for model densities with pressure values estimated at $100 \mathrm{~km}$ for the measured $\mathrm{O}_{2}$ temperature values.

\section{Results and discussion}

As we know that middle atmosphere is dominated by a variety of dynamical features of transient nature, we derive the Rayleigh lidar temperature profiles using the traditional as well as modified scheme for time " $T$ " and average the profiles for $\pm 0.25 \mathrm{~h}$ for a comparison. The time " $T$ " is chosen when the SABER passes were available for a grid of latitudes 09-19 $9^{\circ} \mathrm{N}$ and longitudes $74-84^{\circ} \mathrm{E}$ so that an instantaneous comparison can be made. With regard to the Rayleigh lidar at Gadanki, it is important to state that signal-to-noise 


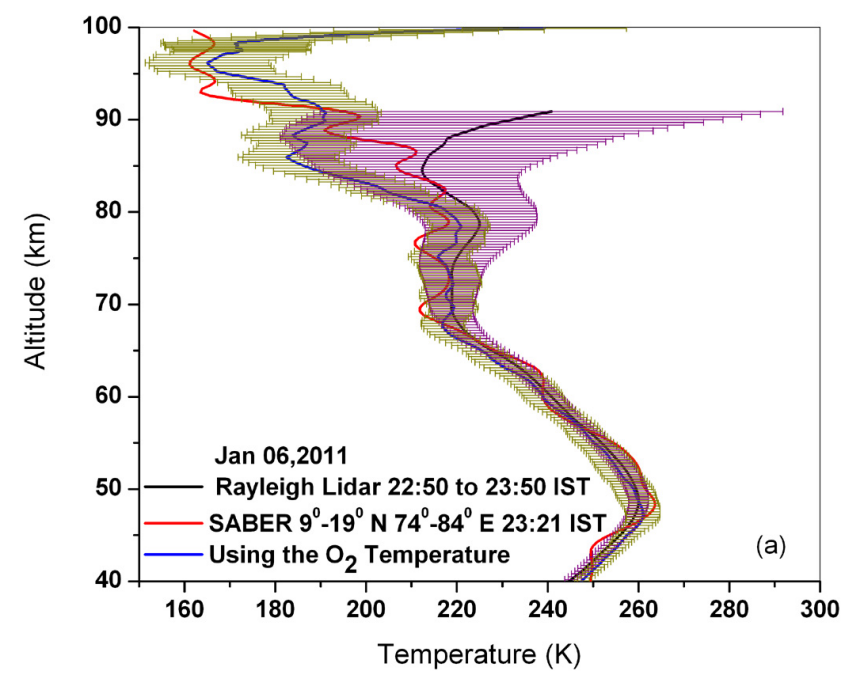

Fig. 1a. Rayleigh lidar temperature profiles and associated standard deviations deduced with the help of CIRA-86 model temperatures (solid black lines with purple standard deviations) and $\mathrm{O}_{2}$ airglow temperatures (dark blue lines with yellow standard deviations) for the backscatter data of 6 January 2011. Shown in red lines are the SABER estimates for a grid of $9-19^{\circ} \mathrm{N}$ and $74-84^{\circ} \mathrm{E}$ for instantaneous comparison.

ratio of the received photon statistics becomes poor above $90 \mathrm{~km}$. However, we found that the standard deviations converge at higher altitudes when the starting values are taken at $\sim 100 \mathrm{~km}$ from the CIRA- 86 model instead of $\sim 90 \mathrm{~km}$. Another important aspect is that the $\mathrm{O}_{2}$ airglow layer represents $95 \pm 5 \mathrm{~km}$, which we use in the temperature retrieval process as a representative temperature at $\sim 100 \mathrm{~km}$. This may vary a bit from actual values but still represents $100 \mathrm{~km}$ better than the model values. This approximation may also suggest that large differences of starting values from the real ones may create large changes in the observed thermal structures in terms of standard deviations and hence the precision of measurements.

Figure 1a shows deduced temperature profiles from the Rayleigh backscatter signals with traditional (black solid lines with purple standard deviations) and modified (dark blue lines with yellow standard deviations) retrieval methods for 6 January 2011 data. Solid red line shows the average of two SABER profiles (shown in Fig. 1b) available in the above mentioned grid for a comparison. We note that lidar temperature profiles that use existing traditional method start deviating from SABER values from $70 \mathrm{~km}$. On the other hand, the profiles that use the $\mathrm{O}_{2}$ temperature (averaged for corresponding time, i.e. $\pm 0.25 \mathrm{~h}$ ) provide a good comparison to the SABER values till $95 \mathrm{~km}$ altitudes. It is worth mentioning that the profiles obtained with traditional method above $90 \mathrm{~km}$ are not shown because of their large differences from SABER and very large standard deviations. As mentioned earlier, the use of the CIRA- 86 model values at $\sim 95 \mathrm{~km}$ at

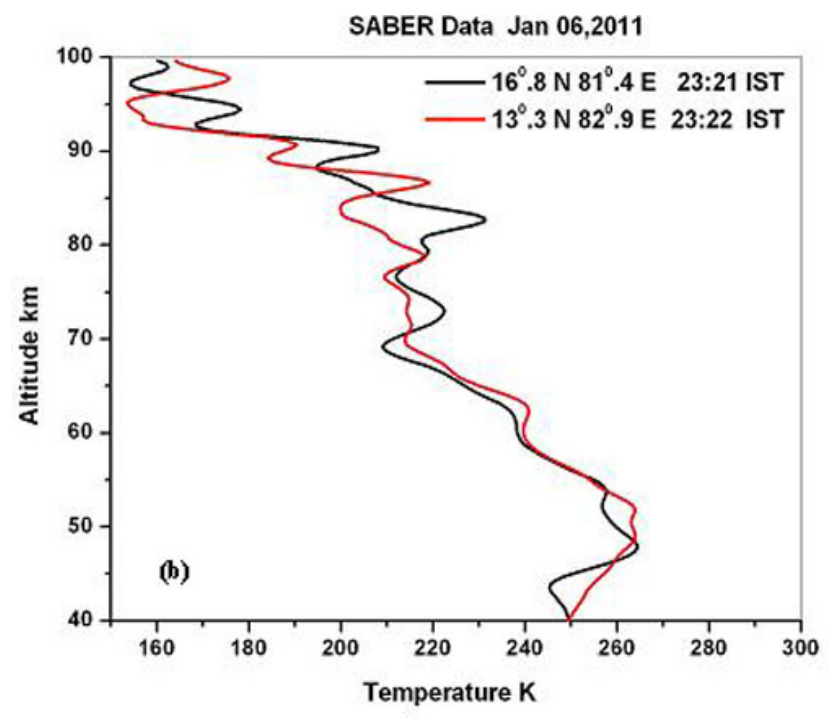

Fig. 1b. The individual SABER profiles in the used grid. It is evident that large amplitudes of wave structures make significant difference within a narrow latitude-longitude separation.

starting altitude also do not bring improvements. However, we note much smaller standard deviations when $\mathrm{O}_{2}$ temperatures are used as starting temperatures at $\sim 100 \mathrm{~km}$. In fact, it is only an approximate value for $100 \mathrm{~km}$. Also noteworthy are the differences between SABER values and the temperatures (obtained with the modified method) at $80-95 \mathrm{~km}$ regions where both show large wave-like oscillatory features. This is because (i) the gravity wave fields are highly variable and transient in nature so change of gravity wave phases within $1-2^{\circ}$ locations may provide an apparent difference as noted in this study; and (ii) that SABER pass is not having exact coincidences, which is evident in Fig. 1b. One may note that near coincident SABER profiles show large oscillatory features in data with somewhat opposite phase within a short spatial difference. In the light of above, we trust that agreement between the modified Rayleigh lidar profiles and SABER values are very good till $95 \mathrm{~km}$ altitudes.

We performed similar a analysis on 27 January 2011; data and results are shown in Fig. 2a. Similar to the earlier case, on this night also, data reveal large oscillatory features. The results of traditional method for Rayleigh lidar temperature estimation show a good comparison with average SABER values till $65 \mathrm{~km}$, while the modified method results in a better temperature profile and good agreement with SABER values up to about $95 \mathrm{~km}$ altitude. In comparison to SABER data, which show large oscillatory features, the modified method temperature profiles reveal a large temperature inversion to occur at $80-90 \mathrm{~km}$ altitudes. The individual SABER temperature profiles for the chosen grid are shown in Fig. 2b. Note that no SABER pass was coincident over the Gadanki location, which possibly is the reason for the observed differences in the variability noted in upper 


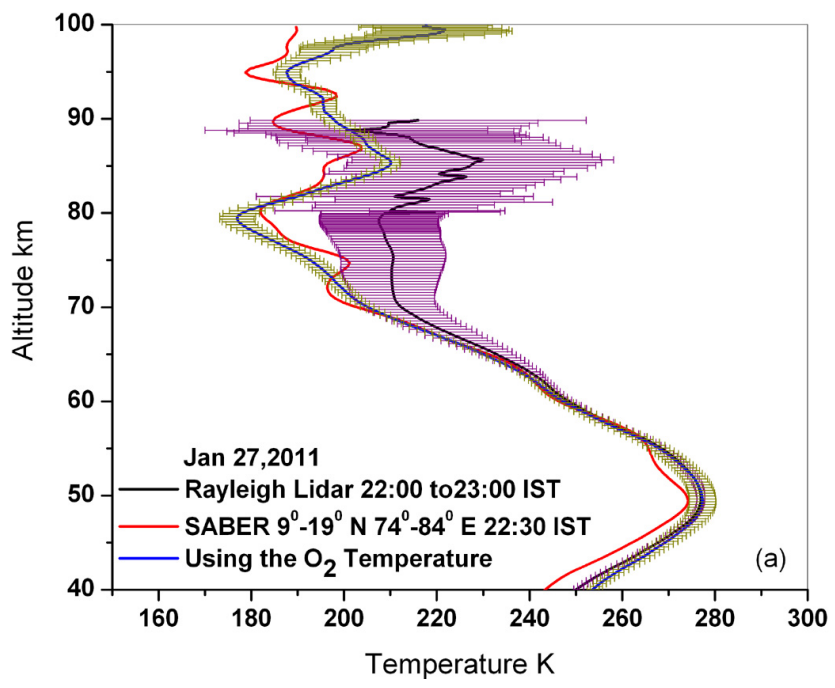

Fig. 2a. Same as Fig. 1a but for 27 January 2011.

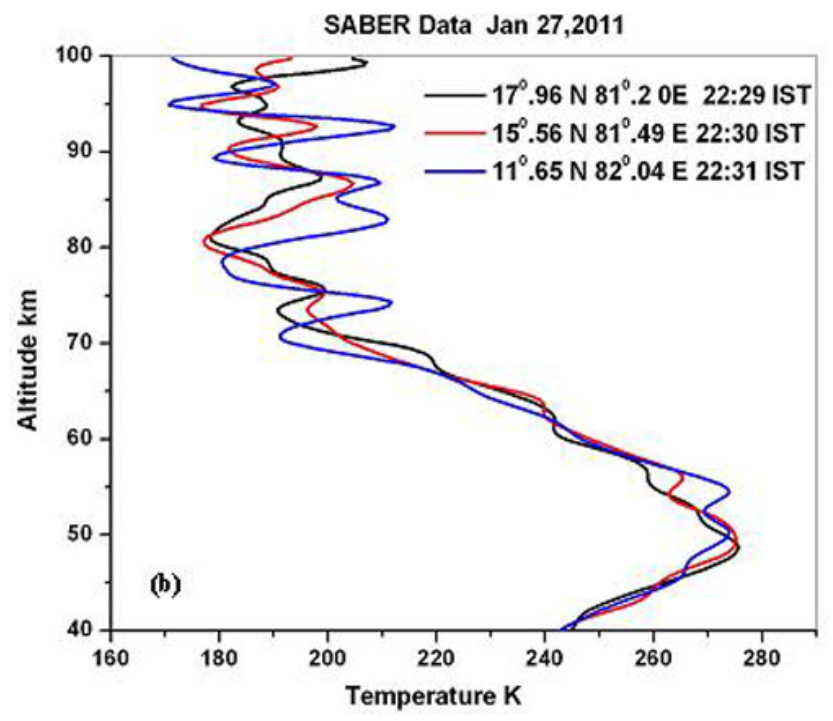

Fig. 2b. Same as Fig. $1 b$ but for 27 January 2011.

mesospheric temperatures. We believe that such a comparison is very good considering a highly dynamic condition owing to the non-linear interaction and dissipation of gravity waves at upper mesospheric altitudes.

The 10 February 2011 was another night when simultaneous Rayleigh lidar and MLTP observations were made (not shown in figures). Similar to other two cases, on this night also the Rayleigh lidar temperature profiles with modified method provide better comparison with SABER values. The improved altitude coverage of Rayleigh lidar by using the new method is understandable due to the fact that a recent study based on two year of mesospheric temperature observations of $\mathrm{OH}(\sim 85)$ and $\mathrm{O}_{2}(\sim 95 \mathrm{~km})$ emissions show large differences from model values (Taori et al., 2012b), and

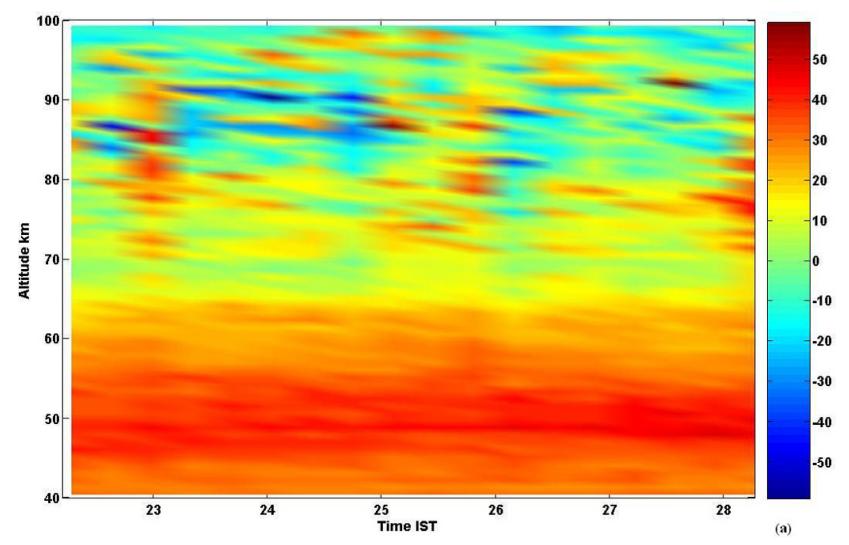

Fig. 3a. The temporal variability of mean temperature deviations (from the mean profile) on 6 January 2011. One may note large amplitudes of waves and their propagation indicating the potential of improvised lidar profiles.

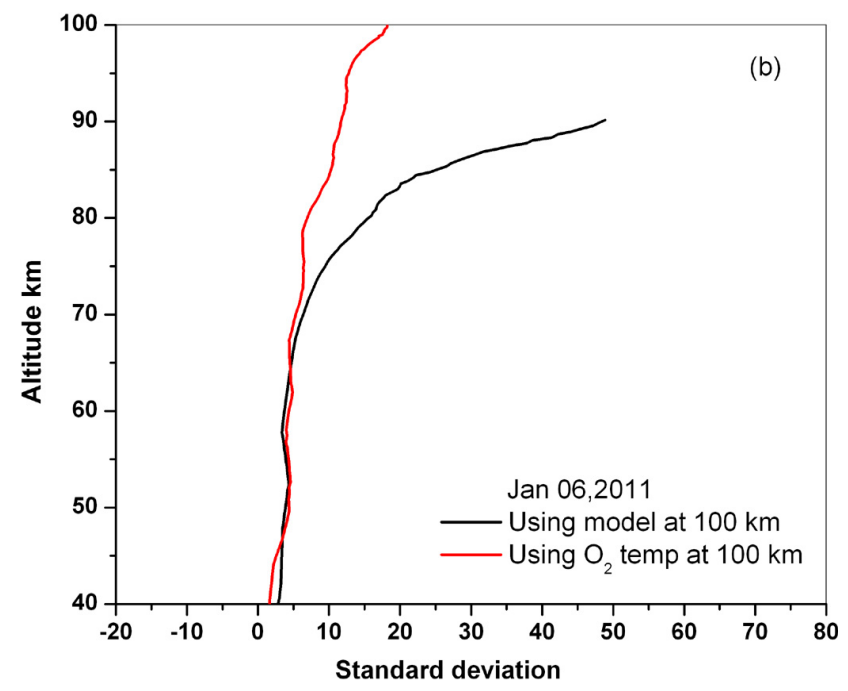

Fig. 3b. The standard deviations for hourly averaged temperature profiles (on 6 January 2011) with improved (red lines) and traditional (black lines) methods.

hence an improper starting value in the lidar temperature retrieval algorithm.

Further, as an aim of improvement in the lidar measurements is to study the variability of short period wave features, we analyze the lidar data with modified temperature retrieval method for $20 \mathrm{~min}$ integration on 6 January 2011 data. Figure 3a shows the temperature perturbations (deviations from the mean profile) throughout the night. Large amplitudes of short period waves are observed in data at 40 to $95 \mathrm{~km}$ region. This may be due to the fact stated in the previous paragraph that if the starting temperature has large difference from the actual temperatures, the downward propagation of error will affect the observed variability. Hence, the variability may be masked by large standard deviations. The standard 
deviations for one hour average profiles are shown in Fig. 3b, where modified temperature retrieval method gives acceptable standard deviations in the temperature estimates up to $\sim 95 \mathrm{~km}$ altitudes. It is evident that at $\sim 90 \mathrm{~km}$, to study the short period wave features, the standard deviations arising from photon statistics are very large in case of the traditional methods.

In summary, the use of $\mathrm{O}_{2}$ temperatures for the Rayleigh lidar temperature retrieval algorithm improves the quality of measurements in terms of altitude and temporal coverage. Such improvement can be utilized to study the short period wave characteristics, and substantial information can be gathered on temporal as well as altitudinal structures. In the present study, deviations noted from SABER estimates put emphasis on the large variability at upper mesospheric altitudes rather than the shortcoming of modified temperature retrieval method. It is also important to note that airglow layer also exhibits variability from one season to other; however, variation in the layer altitude is not more than $5 \mathrm{~km}$ and as the airglow layer thickness is $\pm 5 \mathrm{~km}$, using $95 \mathrm{~km}$ $\mathrm{O}_{2}$ airglow temperatures as a representative value would not make a large difference. A data base building for simultaneous Rayleigh lidar and MLTP measurements is in progress, which will provide climatology of short period variability at upper mesospheric altitudes.

\section{Conclusion}

We have shown for the first time that by using $\mathrm{O}_{2}$ temperatures derived from airglow measurements as input in Rayleigh lidar temperature retrieval algorithm, one can derive temperature information till $95 \mathrm{~km}$. The standard deviations in photon statistics are found to be improved when modified method is utilized. This improvisation enables the study of short period wave features at upper mesospheric altitudes with high temporal resolution. We believe that such simultaneous measurements will immensely improve our knowledge of mesosphere-lower thermosphere coupling processes.

Acknowledgements. This work is supported by Department of Space, Govt. of India.

Topical Editor C. Jacobi thanks one anonymous referee for her/his help in evaluating this paper.

\section{References}

Chandra, H., Sharma, Som, Acharya, Y. B., and Jayaraman, A.: A Rayleigh lidar study of the atmospheric temperature structure over Mt. Abu, India, J. Ind. Geophys. Union, 9, 279-298, 2005.

Dou, X., Li, T., Xu, J., Liu, H.-L., Xue, X., Wang, X., Leblanc, T., McDermid, I. S., Hauchecorne, A., Kekhut, P., Bencherif, H., Heinselman, C., Steinbrecht, W., Mlynczak, M., and Russell III, J. M.: Seasonal oscillations of middle atmosphere temperature observed by Rayleigh lidars and their comparisons with
TIMED/SABER observations, J. Geophys. Res., 114, D20103, doi:10.1029/2008JD011654, 2009.

Dyrland, M. E., Hall, C. M., Mulligan, F. J., Tsutsumi, M., and Sigernes, F.: Improved estimates for neutral air temperatures at $90 \mathrm{~km}$ and $78^{\circ} \mathrm{N}$ using satellite and meteor radar data, Radio Sci., 45, RS4006, doi:10.1029/2009RS004344, 2010.

Hocking, W. K.: Dynamical coupling processes between middle atmosphere and lower ionosphere, J. Atmos. Terr. Phys., 58, 735752, 1996.

Hauchecorne, A. and Chanin, M. L.: Density and temperature profiles obtained by lidar between 35 and $70 \mathrm{~km}$, Geophys. Res. Lett., 7, 565-568, 1980.

Fritts, D. C. and Alexander, M. J.: Gravity wave dynamics and effects in the middle atmosphere, Rev. Geophys., 41, 1003, doi:10.1029/2001RG000106, 2003.

Friedman, J. S. and Chu, X.: Nocturnal temperature structure in the mesopause region over the Arecibo Observatory $\left(18.35^{\circ} \mathrm{N}\right.$, $\left.66.75^{\circ} \mathrm{W}\right)$ : Seasonal variations, J. Geophys. Res., 112, D14107, doi:10.1029/2006JD008220, 2007.

Meriweather, J. W.: Ground based measurements of mesospheric temperatures by optical means, in: International Council of Scientific Unions Middle Atmosphere Program Hand book MAP, vol. 13, edited by: Vincent, R., pp. 1-18, NASA, Green belt, Md.., 1984.

Remsberg, E. E., Marshall, B. T., Garcia-Comas, M., Krueger, D., Lingenfelser, G. S., Martin-Torres, J., Mlynczak, M. G., Russell, J. M., Smith, A. K., Zhao, Y., Brown, C., Gordley, L. L., LopezGonzalez, M. J., Lopez-Puertas, M., She, C. Y., Taylor, M. J., and Thompson, R. E.: Assessment of the quality of the Version 1.07 temperature-versus-pressure profiles in the middle atmosphere from TIMED/SABER, J. Geophys. Res., 113, D17101, doi:10.1029/2008JD010013, 2008.

Shepherd, M. G., Liu, G., and Shepherd, G. G.: Mesospheric semiannual oscillation in temperature and nightglow emission, J. Atmos. Sol. Terr. Phys., 68, 379-389, 2006.

Sivakumar, V., Rao, P. B., and Krishnaiah, M.: Lidar studies of stratosphere and mesosphere thermal structure over a low latitude: Comparison with satellite and models, J. Geophys. Res., 108, 4342, doi:10.1029/2002JD003029, 2003.

Takahashi, H., Onohara, A., Shiokawa, K., Vargas, F., and Gobbi, D.: Atmospheric wave induced $\mathrm{O}_{2}$ and $\mathrm{OH}$ airglow intensity variations: effect of vertical wavelength and damping, Ann. Geophys., 29, 631-637, doi:10.5194/angeo-29-631-2011, 2011.

Taori, A. and Taylor, M.: Characteristics of wave induced oscillations in mesospheric $\mathrm{O}_{2}$ emission intensity and temperatures, Geophys. Res. Lett., 33, L01813, doi:10.1029/2005GL024442, 2006.

Taori, A., Dashora, N., Raghunath, K., Russell, J. M., and Mlynczak, M. G.: Simultaneous mesosphere-thermosphereionosphere parameter measurements over Gadanki $\left(13.5^{\circ} \mathrm{N}\right.$, $\left.79.2^{\circ} \mathrm{E}\right)$ : First results, J. Geophys. Res., 116, A07308, doi:10.1029/2010JA016154, 2011.

Taori, A., Kamalakar, V., Raghunath, K., Rao, S. V. B., and Russell III, J. M.: Simultaneous Rayleigh lidar and airglow measurements of middle atmospheric waves over low latitudes in India, J. Atmos. Sol. Terr. Phys., in press, doi:10.1016/j.jastp.2011.06.012, 2012a.

Taori, A., Kamalakar, V., and Jayaraman, A.: First observation of upper mesospheric semi annual oscillations using ground based 
airglow measurements from Indian low latitudes, Adv. Space Res., in press, doi:10.1016/j.asr.2011.12.016, 2012 b.
Thurairajah, B., Collins, R. L., Harvey, V. L., Liberman, R. S., and Mizutani, K.: Rayleigh lidar observations of reduced gravity wave activity during the formation of an elevated stratopause in 2004 at Chatanika, Alaska $\left(65^{\circ} \mathrm{N}, 147^{\circ} \mathrm{W}\right)$, J. Geophys. Res., 115, D13109, doi:10.1029/2009JD013036, 2010. 